\title{
THE EFFECT OF HELIUM-NEON LASER, USING DIFFERENT METHODS AND FREQUENCIES OF RADIATION, ON WOUND HEALING
}

\author{
AL-ZAMILY R.H. ${ }^{1}$ AND AL-SIAIDY W.F. ${ }^{*}$ \\ 1Department of Physics, College of Medicine, Al-Qadisiya University, Al-Dewaniya, Iraq. \\ 2Department of Physics, College of Medicine, Baghdad University, Baghdad, Iraq. \\ *Corresponding Author: Email-wijdanfmh@googlemail.com
}

Received: October 20, 2013; Accepted: January 09, 2014

\begin{abstract}
He-Ne laser $632.8 \mathrm{~nm}$ plays an important role in wound healing. The aim of this research is to demonstrate the effect of He-Ne Laser on healing of deep wounds in rats employing : I-different methods of irradiation. The first method of irradiation is by a Laser beam spot of $4 \mathrm{~mm}$ in diameter. The second method, the spot Laser beam diameter was expand to $1 \mathrm{~cm}$ by a converging lens, to produce a uniform irradiation on the entire wound length. II-different irradiation frequencies: (1) every other day, (2) daily, and (3) at the first post-operative day only. Eighty eight young male rats were used in this work, they divided in to four groups. The first group consists thirty two rats, which irradiated by $\mathrm{He}-\mathrm{Ne}$ laser at the first post-operative day only. The second group consists twenty four rats which was exposed to laser every other day. The third group contains twenty four rats was exposed daily. Finally, the fourth group consists eight rats, which was regarded as a control group. A biopsy was taken from all irradiated rats for histological examination at 1, 3, 5, and 7 days post operatively. The results demonstrate a clear promoter of wound healing in irradiated groups. But the best one was found in group treated by He-Ne laser with lens, irradiated every other day.
\end{abstract}

Keywords- Helium-Neon Laser, Radiation, Wound Healing, histological examination

Citation: Al-Zamily R.H. and Al-Siaidy W.F. (2014) The Effect of Helium-Neon Laser, Using Different Methods and Frequencies of Radiation, on Wound Healing. International Journal of Medical and Clinical Research, ISSN: 0976-5530 \& E-ISSN: 0976-5549, Volume 5, Issue 1, pp.-274 -276 .

Copyright: Copyright@2014 Al-Zamily R.H. and Al-Siaidy W.F. This is an open-access article distributed under the terms of the Creative Commons Attribution License, which permits unrestricted use, distribution and reproduction in any medium, provided the original author and source are credited.

\section{Introduction}

Wound healing is a complex processes that involve series of events. During the past 20 years there have been numerous reports indicating the effect of Low Level Laser Therapy (LLLT) in the facilitation of the wound healing. Laser therapy stimulates the production of fibroblasts, the building blocks needed to create collagen which replace old or repair damaged tissue [1,2]. Furthermore LLLT increases the formation of new capillaries within the damaged tissues, this mean more blood supply to the injury site [3]. The effect of low energy laser in vitro on cells is dose dependent [4] as well as wavelengths [5]. Therefore, employing the correct power density, exposure time, are the most important parameters to achieve the bio-stimulation effect. In vivo, it's difficult to assess a systemic dose and method of irradiation. Therefore a series of studies have been carried out evaluating the influence of LLLT in wound healing using different laser wavelengths, doses, methods, and frequencies of irradiation on animals. A number of studies confirmed the efficiency of He-Ne laser $(632.8 \mathrm{~nm})$ in accelerating wound healing $[6,7]$. But the efficiency of He-Ne laser in wound healing progressing remains un-established suffering a lack of dose standardization. The quantitative dose response may be related to the wound type, size, and methods of irradiation. Some workers irradiated the total wound length by the laser spot beam of 1-2 $\mathrm{mm}$ in diameter, at one point above the area of injury [6]. In other studies the laser beam spot increased to cover the total wound length $[8,9]$. But Hussein, et al [10] irradiated the total wound incision length spot by spot. Other reason cause dose- response controversy may be arise from the frequencies of irradiation. Many workers irradiated the wound incision daily [6,11], while others irradiated every other day [12,13]. But Yasukan, et al [13] exposed wound incision to He-Ne laser beam at the 1 day only, or at 3 day only, or at 5 day only post operation. Generally, in all these methods of irradiation, He-Ne laser enhance wound healing.

The aim of this study is to evaluate the effect of $\mathrm{He}-\mathrm{Ne}$ laser irradiation on wound healing on rats, using constant energy (dose), with different methods and frequencies of irradiation.

\section{Materials and Methods}

Eighty eight adult rat male, age (2-3) months, and weight approximately (250-500 g), were used in this study. The rats were randomly divided into (4) groups. Eight animals, non-irradiated, regarded as a control group. The other (80) animals were exposed to laser irradiation. The site of incision area in anesthetized animal was shaved and disinfected. A deep wound of length $1 \mathrm{~cm}$ were made on one side of dorsal in each animal. The wounds were left without dressing. The animals were kept in cleaned mesh cage to prevent any 
contamination.

\section{He-Ne laser Irradiation}

A continuous He-Ne laser (JGQ-250, china) of wavelength 632.8 $\mathrm{nm}$ was employed. Its output power is $0.85 \mathrm{~mW}$, and a beam spot of $4 \mathrm{~mm}$ in diameter. Irradiation was done at the second day following surgery by:

First Method: The wound incision was exposed to the laser beam spot of $4 \mathrm{~mm}$ in diameter. The irradiation was done at the middle of the wound length of $1 \mathrm{~cm}$ for 3 minutes. This produces an energy of (0.153) Joule, and Energy per unit area $=0.153 / 0.125=1.224 \mathrm{~J} /$ $\mathrm{cm}^{2}$.

Second Method: The wound was exposed to He- Ne laser covering the whole wound length, by increasing the laser beam diameter to $1 \mathrm{~cm}$ using a converging lens, to perform a uniform irradiation on the whole wound length. The final effective power at the rat skin surface (wound) was $0.7 \mathrm{~mW}$, measured by laser power meter, (FAMWA) model modikem LP1. Japan. In this method of irradiation, the exposure time was increased to $3.7 \mathrm{~min}$, in order to deliver exactly the same amount of energy to the wound $(0.153 \mathrm{~J})$ as in the first method of irradiation. Even though the final energy density performed on the wound in this procedure is $0.2 \mathrm{~J} / \mathrm{cm}^{2}$, which is lower than the energy density in the first method of irradiation. The 80 animals were irradiated at the first post-operative day with 3 different irradiation frequencies and by the two methods of laser irradiation. The first day is the 24 hour following surgery.

Group-1: Consist thirty two animals subdivided into two equal groups. The first sixteen animals were irradiated by laser spot (first method), and the other sixteen irradiated by the second irradiation method. All animals in this group were irradiated early only at the first day following surgery. The wound skin specimen for histopathological examination was taken at $(1,3,5,7)$ post- operative days, in groups of three each. The specimen at the first day was taken 8 hours after irradiation. The specimens was kept in neutral formalin for the histopathological examination. Then skin gap was stitched by nylon sutures.

Group-2: Consist 24 animals, twelve of them were irradiated by laser spot, and the other by the expand laser beam daily. The wound specimen was taken at the $(1,3,5,7)$ post- operative days.

Group-3: Animals in this group were irradiated every other day (1st, 3rd, 5th, 7th day). This group consists (24) animals subdivided in two equal groups. Each sub group irradiated by $\mathrm{He}-\mathrm{Ne}$ Laser using one of the mentioned methods. Then the wound skin specimen was taken on the 1, 3, 5, 7 post-operative days.

The histopathological examination was performed to evaluate the amount of inflammatory cells, the microscopic characteristics appearance of Fibroblast, Granulation tissue, and Epithelial cells for each specimen.

\section{Results}

All the histological results were summarized in [Fig-1]. The histological examination and the experimental observation results indicated that the low energy photons from $\mathrm{He}-\mathrm{Ne}$ laser facilitate wound healing. But the results were different when comparing the group's treated with different methods and frequencies of irradiation. A positive reaction was found from the first day of irradiation in comparable with control. The results revealed maximum inflammatory cells infiltration in the control group, and a moderate in the treated groups.
Furthermore the presence of fibroblast and epithilization on group treated by laser with lens was appeared earlier than the group treated by laser spot [Fig-1].

On the third day, the marks of wound healing was very slow on the control group in comparable with treated groups, specially the wounds irradiated every other day. The histological changes indicated better healing in the groups treated by laser with lens than laser spot.

On the five and seven days post operation the results demonstrated faster epithelization and complete wound healing with restoration of the epidermis that mimic the normal condition, in group treated by laser+ lens irradiated every other day, in comparable with the groups exposed to laser spot, and control.

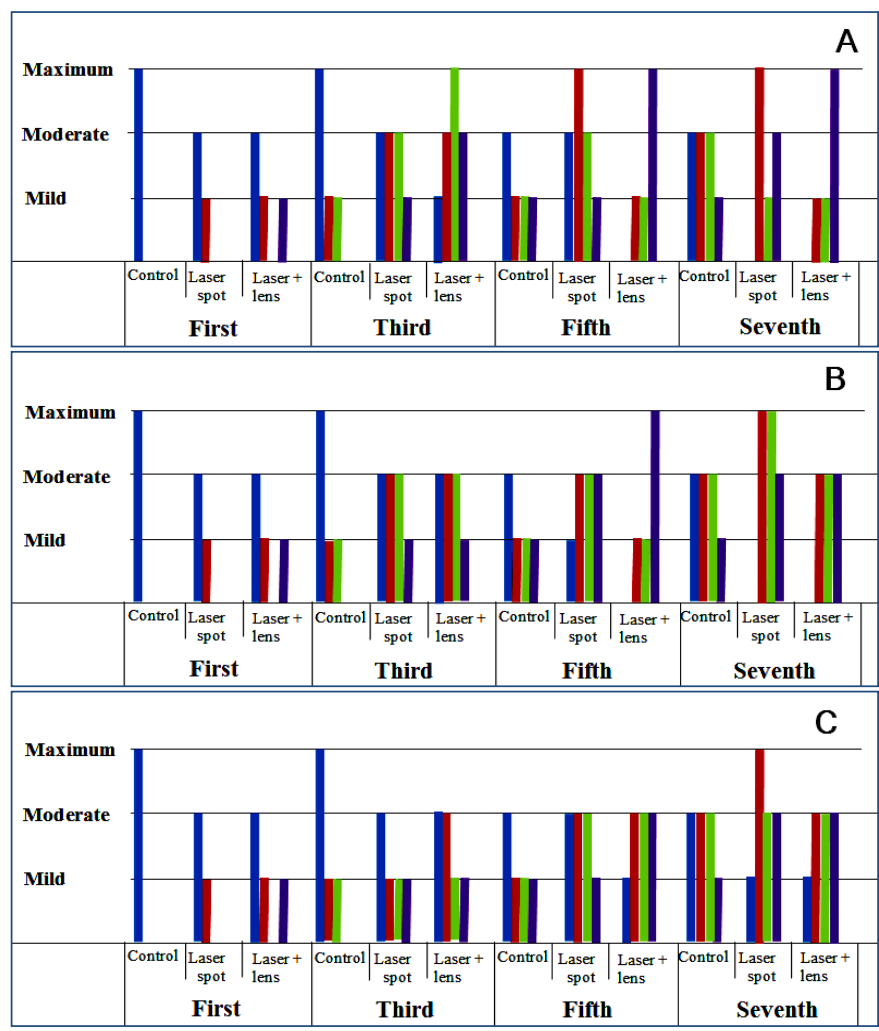

Fig. 1- Irradiated and non- irradiated(control) deep wound healing histological results at the $1,3,5,7$ day post-operative, employing the two irradiated methods (laser spot and laser + lens) for: A- every other day irradiation, B- daily irradiation, C- irradiation at the first post -operative day only. Histological parameters: inflammation (Blue), fibroblast (Red), granulation (Green), \& epithilization (Voilet).

\section{Discussion}

The histological findings demonstrated that wound irradiated by laser with the lens showed the most significant recovery of wound. Such as in the prevention of excessive inflammation and increased formation of fibroblast and granulation tissue. This maybe due to the type of irradiation which covering all wound length and distributed on both side. Therefor it may enhance better blood supply through wound sides. Generally, many studies indicated that, wounds irradiated by laser showed a reduction inflammatory reaction, started at the first post-operative day with a mild appearance of fibroblasts compared with control [14-16]. Many workers reported that laser irradiation inhibits inflammatory cells and cytokines liberation [17,18]. Kami [3] postulated that this anti- 
inflammatory effect of laser may up regulate angiogenesis around the wound causing an increase in blood flow, and thus promoter wound healing. Furthermore, the early appearance of fibroblasts may be one of the most important factors effecting wound healing. Since its play a crucial role in healing of epithelization and granulation tissue $[2,19]$.

Kana, et al [9] reported the probability of laser irradiation inducing fibroblast proliferation through healing mechanism, and Yaskawa, et al [13] suggested the stimulating of collagen synthesis. It is well known that the low energy laser at wavelength of $632.8 \mathrm{~nm}$ can modulate the cell proliferation and release growth factors from fibroblasts $[20,21]$. Laser had been shown to enhance the degranulation of mast cells that results in histamine production, which tend to accelerate the inflammatory cascade. As the inflammatory process progresses more rapidly, the proliferative phase of healing begins earlier, subsequently enhancing the wound healing process [9].

In this study, the degree of healing progress, using daily irradiations, was intermediate between the every other day irradiation and the first day irradiation only. This results may be due the bioinhibition mechanism which occurs when the doses exceeding the stimulatory range in cells. The inhibition with higher dose is possibly produced of dry harder scar [22]. In this study, scar formation, appeared at the seven days post operation, in group treated by laser spot irradiated daily. This may be due to the rising in fibroblast and granulation tissue more than normal. Hallman, et al [23] revealed that, the excessive cumulative effects of daily exposure for several days irradiation may reversed any initial beneficial effects of laser. Mcguff, et al [24] reported that, higher dose leading to direct thermal destruction of tissues.

\section{Conclusions}

- The study demonstrated that, the He-Ne laser was effective in open wounds healing which showed better restoration and faster repair compared to the control group wounds.

- Deep wounds irradiated by laser every other day with a lens show better results than the daily and one day irradiation.

- The correct energy with an appropriate method, and frequency of irradiation are important parameters to achieve the biostimulation effect in wound healing. He-Ne laser cause acute inflammation, and more rapid fibroblast proliferation, these factors may enhance earlier wound healing.

Conflicts of Interest: None declared.

\section{References}

[1] Slatter D. (1995) Wound Healing and Specific Tissue Regeneration. Text book of Small Animal Surgery, W.B. Saunders Company, London.

[2] Baxter G.D., Diamantopoulos C., O'kane S., and Shields T.D. (1999) Therapeutic Lasers, Theory and Practice, Churchill living ston, London.

[3] Kami T. (1990) Keio Journal of Medicine, 39(1), 06-13.

[4] Oshiro T., Calderhead R.G. (1998) Low-level Laser Therapy: A Practical Introduction, Chichester Wilet and Sons.

[5] Karu T.I. (1990) Photochemistry and Photobiology, 52(6), 10891098.

[6] Peccin M.S., Renno A.C.M., de Oliveira F., Giusti P.R. and Ribeiro D.A. (2012) Journal of Cosmetic and Laser Therapy, 14
(6), 286-289.

[7] Maiya A.G., Kumar P. and Nayak S. (2009) Indian Journal of Dermatology, 54(4), 323-329.

[8] Al-Watban F.A.H. and Andres B.L. (2001) Lasers in Medical Science, 16(4), 267-275.

[9] Kana J.S., Hutschenreiter G., Haina D., Waidelich W. (1981) Archives of Surgery, 116(3), 293-296.

[10]Hussein A.J., Alfars A.A., Falih M.A., Hassan A.N.A. (2011) North American Journal of Medical Sciences, 3(4), 193-197.

[11]Bisht D., Gupta S.C., Misra V., Mital V.P. and Sharma P. (1994) The Indian Journal of Medical Research, 100, 43-46.

[12]David R., Nissan M., Cohen I. and Soudry M. (1996) Lasers in Surgery and Medicine, 19(4), 458-464

[13]Yasukawa A., Hrui H., Koyama Y., Nagai M., and Takakuda K. (2007) The Journal of Veterinary Medical Science, 69(8), 799-806.

[14]Ghamsari S.M., Taguchi K., Abe N., Acorda J.A., Motoyoshi S., and Yamada H. (1997) Veterinary Surgery, 26(2), 114-120.

[15]Kass A. (1990) Biomedizinische Technik. Biomedical Engineering, 35(7-8), 154-157.

[16]Anneroth G., Hall G., Ryden H. and Zetterqvist L. (1988) British Journal of Oral and Maxillofacial Surgery, 26(1), 12-17.

[17]Aimbire F., Albertine R., de Magalhães R.G., Lopes-Martins R.A.B., Castro-Faria-Neto H.C., Zângaro R.A., Chavantes M.C. and Pacheco M.T.T. (2005) Lasers in Medical Science, 20(1), 11-20.

[18]Shibata Y., Ogura N., Yamashiro K., Takashiba S., Kondoh Y., Miyazawa K., Matsui M. and Abiko Y. (2005) Lasers in Medical Science, 20(3-4), 109-113.

[19]Markolf H.N. (2003) Laser Tissue Interaction, Fundamental and Application, Spinger Verlag, Berlin.

[20]lba Y., Shibata A., Kato M. and Masukawa T. (2004) International Immuno Pharmacology, 4(14), 1873-1880.

[21]Fitz-Ritson D. (2001) The Journal of the Canadian Chiropractic Association, 45(1), 26-33.

[22]O'Leary R., Wood E.J., and Guillou P.J. (2002) European Journal of Surgery, 168(10), 523-534.

[23]Hallman H.O., Basford J.R., O'Brien J.F., Cummins L.A. (1988) Lasers in Surgery and Medicine, 8(2), 125-129.

[24]Mcguff P.E., Deterling R.A., Gottlieb L.S., Fahimi H.D., Bushnell D., Roeber F. (1965) Fed. Proc., 24, 150-154. 